Supplement of Biogeosciences, 18, 5247-5264, 2021 https://doi.org/10.5194/bg-18-5247-2021-supplement (C) Author(s) 2021. CC BY 4.0 License.

(c) (1)

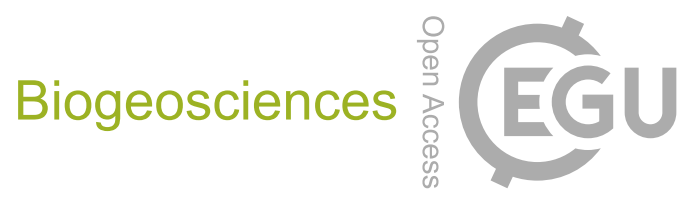

Supplement of

\title{
Long-term spatiotemporal variations in and expansion of low-oxygen conditions in the Pearl River estuary: a study synthesizing observations during 1976-2017
}

Jiatang Hu et al.

Correspondence to: Jiatang Hu (hujtang@ mail.sysu.edu.cn)

The copyright of individual parts of the supplement might differ from the article licence. 


\section{Materials and methods}

\subsection{Sample collections, measurements, and data quality control}

For the Datasets 1-4 compiled (Table 1), the sample collection, storage and transportation, seawater analysis, and data processing and quality control were strictly operated in accordance with the specifications of oceanographic survey (e.g.,

25 GB/T 12763-1991; GB/T 12763-2007) and the specifications for marine monitoring (e.g., GB 17378-1998; GB 173782007) issued by the National Standard of P.R. China. By following these specifications, three-point samples were collected from the surface ( $0.5 \mathrm{~m}$ below the sea surface), half depth, and bottom (0.5-2 $\mathrm{m}$ above the sea bed) when the water depth was > $10 \mathrm{~m}$; two-point samples were collected from the surface and bottom when the depth was between 5 and $10 \mathrm{~m}$; and only surface sample was collected when the depth was $<5 \mathrm{~m}$. Temperature was measured on board using

30 a thermometer, and salinity was measured with an induction salinometer in the laboratory. Ammonia $\left(\mathrm{NH}_{4}\right)$, nitrate $\left(\mathrm{NO}_{3}\right)$, and phosphate $\left(\mathrm{PO}_{4}\right)$ were analyzed using the indophenols blue spectrophotometric, $\mathrm{Cd}$ reduction, and phosphorus molybdenum blue spectrophotometric methods, respectively. SSC was measured by the gravimetric method, and chl $a$ was measured using a spectrophotometer after the acetone extraction. As for DO, water samples were collected in brown frost-mouth bottles, immediately fixed with solutions of $\mathrm{MnCl}_{2}$ and $\mathrm{KI}$ on board, and were analyzed using the

35 Winkler titration method (Parson et al., 1984). According to the requirements of data quality control, double-parallel samples were obtained to ensure the accuracy and comparability of the sample measurements.

\section{References}

Parsons, T.R., Maita, Y., Lalli, C.M.: A Manual of Chemical and Biological Methods for Seawater Analysis, Pergamon Press,

40 Oxford, https://doi.org/10.1016/C2009-0-07774-5, 1984. 

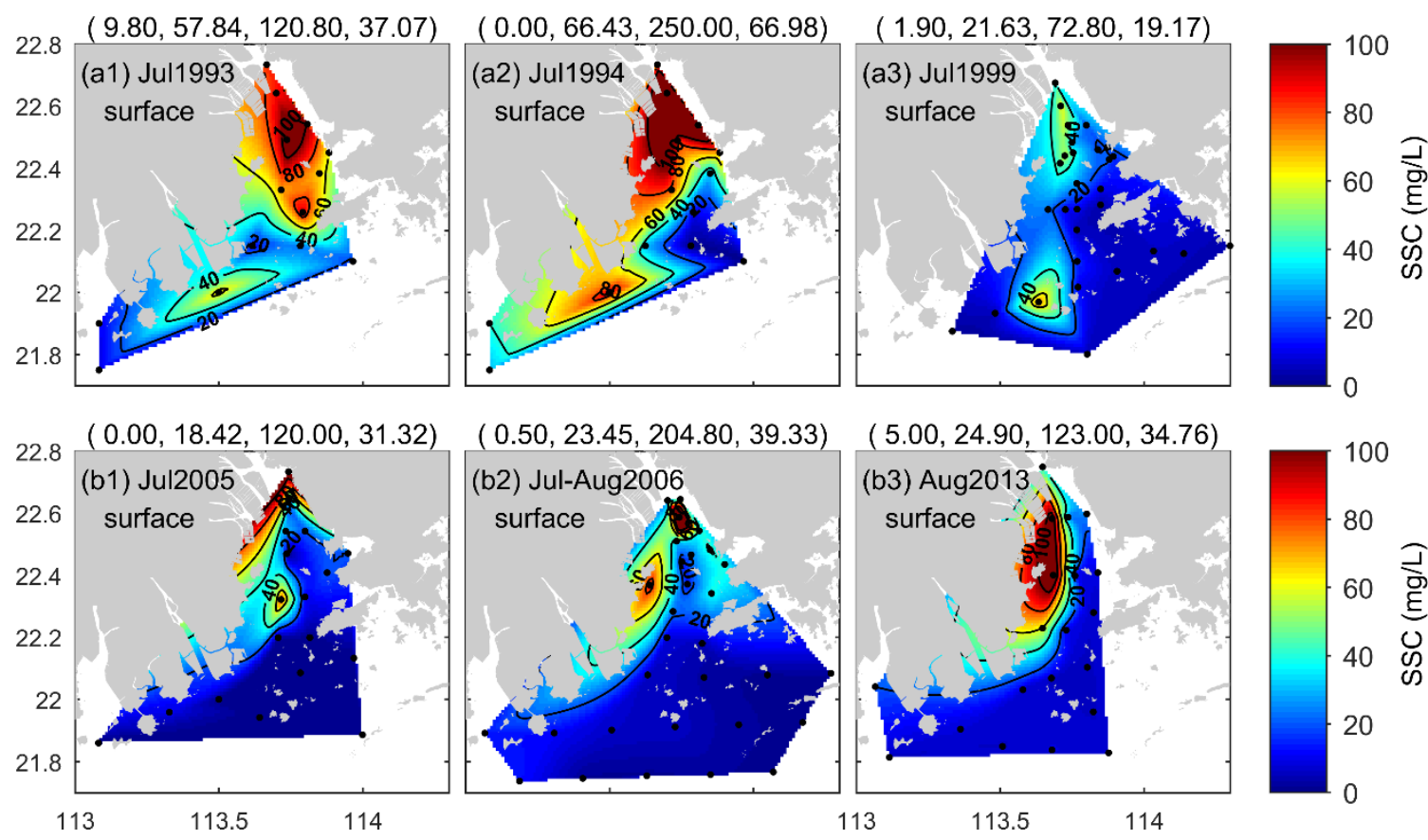

45 Figure S1. Spatial distributions of suspended sediment concentrations (SSC) in the surface waters of the PRE in summer. Note that the numbers in brackets in the titles are the minimum, mean, maximum, and standard deviation values of SSC in sequence.
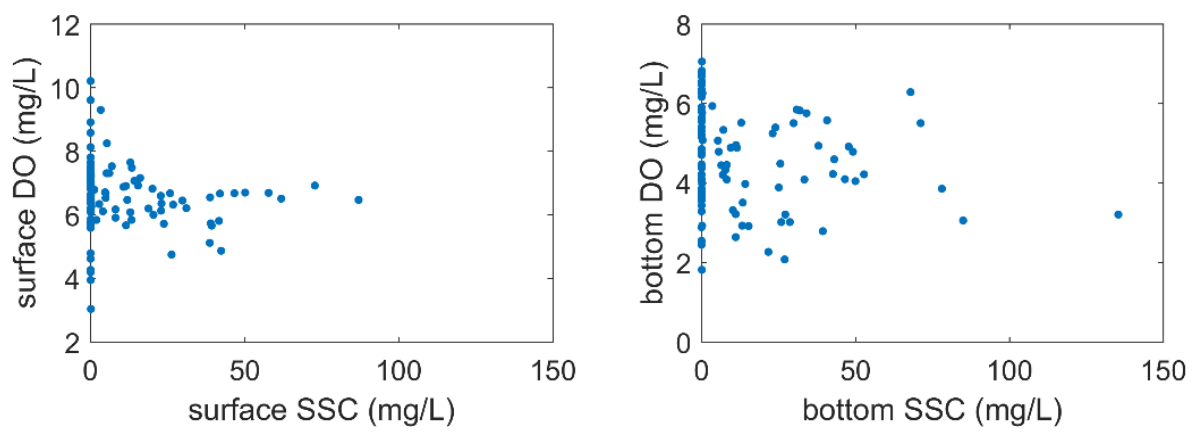

Figure S2. Dissolved oxygen (DO) versus SSC at the surface and bottom of the PRE in summer. 